\title{
The incidence of high-frequency hearing loss after microvascular decompression for trigeminal neuralgia, glossopharyngeal neuralgia, or geniculate neuralgia
}

\author{
Parthasarathy Thirumala, MD, MS, $, 1,2$ Kristin Meigh, NRP, ${ }^{3}$ Navya Dasyam, MBBS, ${ }^{1}$ \\ Preethi Shankar, ${ }^{1}$ Kanika R. K. Sarma,, Deepika R. K. Sarma, ${ }^{1}$ Miguel Habeych, MD, MPH, ${ }^{1}$ \\ Donald Crammond, $\mathrm{PhD},{ }^{1}$ and Jeffrey Balzer, $\mathrm{PhD}{ }^{1}$ \begin{abstract}
Pittsburgh, Pennsylvania
\end{abstract} \\ Departments of ${ }^{1}$ Neurological Surgery and ${ }^{2}$ Neurology, and ${ }^{3}$ Schools of Emergency Medicine and Medicine, University of
}

\begin{abstract}
OBJECT The primary aim of this study was to evaluate the incidence and discuss the pathogenesis of high-frequency hearing loss (HFHL) after microvascular decompression (MVD) for trigeminal neuralgia (TGN), glossopharyngeal neuralgia (GPN), or geniculate neuralgia (GN).

METHODS The authors analyzed preoperative and postoperative audiogram data and brainstem auditory evoked potentials (BAEPs) from 93 patients with TGN, 6 patients with GPN, and 8 patients with GN who underwent MVD. Differences in pure tone audiometry $>10 \mathrm{~dB}$ at frequencies of $0.25,0.5,1,2,4$, and $8 \mathrm{kHz}$ were calculated preoperatively and postoperatively for both the ipsilateral and the contralateral sides. Intraoperative monitoring records were analyzed and compared with the incidence of HFHL, which was defined as a change in pure tone audiometry $>10 \mathrm{~dB}$ at frequencies of 4 and $8 \mathrm{kHz}$.
\end{abstract}

RESULTS The incidence of HFHL was $30.84 \%$ on the side ipsilateral to the surgery and $20.56 \%$ on the contralateral side. Of the 47 patients with HFHL, 20 had conductive hearing loss, and 2 experienced nonserviceable hearing loss after the surgery. The incidences of HFHL on the ipsilateral side at 4 and $8 \mathrm{kHz}$ were $17.76 \%$ and $25.23 \%$, respectively, and $8.41 \%$ and $15.89 \%$, respectively, on the contralateral side. As the audiometric frequency increased, the number of patients with hearing loss increased. No significant postoperative difference was found between patients with and without HFHL in intraoperative BAEP waveforms. Sex, age, and affected side were not associated with an increase in the incidence of hearing loss.

CONCLUSIONS High-frequency hearing loss occurred after MVD for TGN, GPN, or GN, and the greatest incidence occurred on the ipsilateral side. This hearing loss may be a result of drill-induced noise and/or transient loss of cerebrospinal fluid during the course of the procedure. Changes in intraoperative BAEP waveforms were not useful in predicting HFHL after MVD. Repeated postoperative audiological examinations may be useful in assessing the prognosis of HFHL. http://thejns.org/doi/abs/10.3171/2014.10.JNS141101

KEY WORDS microvascular decompression; high-frequency hearing loss; trigeminal neuralgia; glossopharyngeal neuralgia; geniculate neuralgia; pure tone audiometry; auditory brainstem response; pain

$\mathrm{S}$ ENSORINEURAL hearing loss after microvascular decompression (MVD) has a reported incidence of $1 \%-23.8 \%$ when performed for trigeminal neuralgia (TGN), 1.5\%-4.2\% for glossopharyngeal neuralgia (GPN), and $22 \%$ for geniculate neuralgia (GN). ${ }^{21,24,25,27}$ Because of the proximity of the cranial nerve VIII to cranial nerves decompressed during the procedure, the audi- tory nerve in many patients is often stretched or damaged, resulting in hearing impairment. Although sensorineural hearing loss after MVD is frequently documented and well understood, high-frequency hearing loss (HFHL) is currently not well recognized. HFHL has been recently reported after MVD for hemifacial spasm (HFS). ${ }^{34}$ It is unclear if similar changes are present after MVD for

ABBREVIATIONS BAEP = brainstem auditory evoked potential; $\mathrm{GN}=$ geniculate neuralgia; $\mathrm{GPN}=$ glossopharyngeal neuralgia; $\mathrm{HFHL}=$ high-frequency hearing loss; $\mathrm{HFS}$ $=$ hemifacial spasm; IPL = interpeak latency; MVD = microvascular decompression; $P T A=$ pure tone average; $T G N=$ trigeminal neuralgia; $w V=W a v e ~ V$. SUBMITTED May 23, 2014. ACCEPTED October 20, 2014.

INCLUDE WHEN CITING Published online May 1, 2015; DOI: 10.3171/2014.10.JNS141101.

DISCLOSURE The authors report no conflict of interest concerning the materials or methods used in this study or the findings specified in this paper. 
TGN, GPN, or GN. Patients with significant HFHL ( $>10$ $\mathrm{dB}$ change in pure tone audiometry) have deficiencies in high-frequency components of speech, such as consonant sounds, and can have difficulties understanding speech in the presence of background noise. ${ }^{34}$ These deficiencies can have a negative impact on lifestyle because these patients may be unable to distinguish words that start and end with similar consonant sounds. Recognizing and understanding the incidence and pathogenesis of HFHL will be helpful in developing strategies to prevent it during MVD in particular and in craniotomies in general. The primary aim of this study was to evaluate the incidence and discuss the pathogenesis of HFHL after MVD for TGN, GPN, or GN.

\section{Methods}

\section{Study Design}

The study evaluated patients who underwent MVD for TGN, GPN, or GN at the University of Pittsburgh Medical Center between 2004 and 2012. The criteria for inclusion were as follows: 1) diagnosis of TGN, GPN, or GN and surgical treatment by MVD; 2) availability of preoperative and postoperative audiometry data; and 3) availability of intraoperative neurophysiological brainstem auditory evoked potential (BAEP) measurements. Patients with no preoperative or postoperative audiograms and without useful intraoperative monitoring data were excluded from the study. The study was approved by the institutional review board for retrospective review of data on human subjects at the University of Pittsburgh. The design of the study and the analysis of the data are intended to be similar to those used in a study published previously by many of the present paper's authors. ${ }^{34}$

\section{Surgical Technique}

The MVD was performed under general anesthesia. With the patients placed in the lateral decubitus position, surgeons performed a small retromastoid craniectomy. The compressing vessel was mobilized by dissection of the arachnoid bands that tethered the vessel, and a Teflon pledget was placed between the vessel and the nerve to attain adequate decompression. Decompression of cranial nerves V, IX, and X was accomplished by techniques such as sectioning of the nervus intermedius to treat TGN, GPN, and GN, respectively. ${ }^{17}$ During the surgery, BAEPs were recorded and closely monitored.

\section{Pure Tone Audiometry}

Pure tone audiometry can be used either for screening or for complete evaluation of hearing deficits. ${ }^{32}$ Preoperative and postoperative audiometry testing is a routine protocol at our institution. Audiometry testing was conducted before and after surgery at frequencies of $0.25,0.5,1,2,4$, and $8 \mathrm{kHz}$ in a quiet testing environment with low levels of background noise that were within American National Standards Institute requirements ${ }^{8}$ with standard equipment: a GSI 61 audiometer with TDH-BOP headphones (both from Grason-Stadler). The hearing threshold in pure tone audiometry was defined as the softest sound a patient could hear at each frequency for $50 \%$ of the series of ascending tones. Testing was done beginning with the ear in which the patient perceived he or she had better hear- ing. If the patient responded to a pure tone presented at a clearly audible level, a 10-dB-down, 5-dB-up pattern was employed by decreasing the tone by $10 \mathrm{~dB}$ until the patient no longer responded and then increasing the tone by $5 \mathrm{~dB}$ until the patient responded. This was the patient's initial ascending response. To check for accuracy, the technician decreased the intensity of the tone by $10 \mathrm{~dB} 1$ more time to check for no response and then increased the tone in 5-dB increments until the patient responded again to the signal. The $\mathrm{dB}$ level at which the patient responded consistently (minimum 2 out of 3 responses in ascending order), was recorded as the air conduction threshold. Then the same tests were performed on the patient's other ear. After the surgery, postoperative audiograms were collected within 7 to 21 days.

The mean of the thresholds measured at $0.5,1$, and 2 $\mathrm{kHz}$ was defined as the pure tone average (PTA). High frequencies were defined as frequencies at 4 and $8 \mathrm{kHz},{ }^{29}$ and HFHL was defined as a change in the pure tone audiometry of $>10 \mathrm{~dB}$ at these frequencies. ${ }^{6}$ The speech discrimination score (the phonetically balanced score) was represented as a percentage and was coupled with the PTA score to determine whether the patient had nonserviceable hearing loss according to the American Academy of Otolaryngology-Head and Neck Surgery classification system. ${ }^{1}$ According to this classification system, nonserviceable hearing loss is defined by Class $\mathrm{C} / \mathrm{D}$, which involves a PTA of $>50 \mathrm{~dB}$ and a speech discrimination score of $<50 \%$. Preoperative and postoperative PTA and phonetically balanced data for both the ipsilateral and the contralateral ear were compared to determine whether a change in class occurred. The presence of conductive hearing loss was also indicated by calculation of an air-bone gap of $>$ $10 \mathrm{~dB}$ at frequencies of $0.5,1$, or $2 \mathrm{kHz}$.

\section{Intraoperative BAEP Monitoring \\ Stimulation and Recording}

Parameters of the BAEP monitoring were set according to the recommended guidelines of the American Clinical Neurophysiology Society. ${ }^{2}$ Baseline BAEPs were obtained preoperatively in our diagnostic laboratory. During surgery, potentials were recorded continuously by stimulation of the ear ipsilateral to the affected side with alternating rarefaction and condensation clicks. A stimulus rate of 12 $\mathrm{Hz}$ was used for optimal resolution of the collected peaks. A click intensity of at least an $85-\mathrm{dB}$ sound pressure level was implemented, and white noise at an intensity of a 65$\mathrm{dB}$ sound pressure level was used to mask the activity in the contralateral ear. Five hundred and twelve trials were averaged over each 12-msec observation interval to obtain interpretable BAEP data. Three channels were used for recording. Channels $1(\mathrm{Cz} / \mathrm{A} 1)$ and $2(\mathrm{Cz} / \mathrm{A} 2)$ were formed between the vertex and the left and right ear mastoid, respectively. Channel $3(\mathrm{Cz} / \mathrm{Cv} 2)$ spanned from the vertex to cervical $\mathrm{C} 2$. Wave $\mathrm{V}(\mathrm{wV})$, the largest component of the BAEP waveform, was analyzed in real time during the procedure. Significant changes in $\mathrm{wV}$ were recorded and reported to the surgeon to monitor brainstem function, to detect ischemia, and to identify perturbations, which are indicators of hearing function. 


\section{Criteria for Significant Change}

Two components of $\mathrm{wV}$ were monitored and compared with baseline responses during the course of the surgery: amplitude and latency. Significant changes in each variable were recorded and reported to the surgeon. A significant change in amplitude took place when $\mathrm{wV}$ decreased to $50 \%$ of its baseline value, and a significant change in latency occurred when wV shifted at least $0.5 \mathrm{msec}$ away from the baseline. In addition, the specified differences in latency or amplitude were required to occur during at least 2 consecutive trials in order to be considered significant and to prevent technical issues from interfering with data collection. A combined remote and onsite model was used for physician interpretation at the University of Pittsburgh Medical Center. ${ }^{30}$

\section{Analysis of Neurophysiological Parameters}

Several aspects of the BAEP waveforms were recorded and analyzed periodically throughout the operation. The latency of Waves I, III, and V, the interpeak latency (IPL) between these waves (wI-III, wIII-V, and wI-V), and the amplitude of Waves III and V were all recorded at 5 specific points in the surgery. First, a baseline waveform was selected prior to the incision after positioning and intubation were completed. The next waveform was selected during the period when the surgeon was opening the dura. The third waveform was noted at the start of significant change, that is, when $\mathrm{wV}$ shifted either $0.5 \mathrm{msec}$ away from the baseline or when the amplitude of $\mathrm{wV}$ decreased to $50 \%$ of its baseline value. A fourth waveform indicating maximum change was noted when $\mathrm{wV}$ was at its greatest latency. Lastly, the "on skin" or last epoch was recorded after the surgery was completed. The increase in latency was reported to the surgeon as the difference in milliseconds between the selected waveform and the baseline waveform. The change in amplitude was reported as a percentage of the baseline value (for example, if the baseline value was 1 and decreased by 0.2 , then it was reported as $80 \%$ of the baseline).

\section{Statistical Analysis}

Intraoperative BAEP changes were compared with preoperative and postoperative audiometric data to determine whether BAEP data were useful predictors of HFHL. Patients were grouped into 2 categories depending on whether they had HFHL. A 2-tailed t-test was used to determine if there was significant statistical difference between patients with HFHL and without HFHL. A p value of $<0.05$ was used to determine statistical significance.

\section{Results}

For this study, 125 patients with TGN, 10 patients with GPN, and 9 patients with GN were considered for inclusion. Patients were not included in the study if any components of the preoperative or postoperative audiogram data were missing. Additionally, patients were excluded if BAEP intraoperative monitoring records were not available. This left 93 patients with TGN, 6 patients with GPN, and 8 patients with GN available for analysis, for a total sample size of 107 patients.

\section{Demographic Variables}

The age, sex, and affected side were compared with the incidence of HFHL on both the ipsilateral and the contralateral sides (Table 1). No significant difference was found between patients with and without HFHL.

\section{Incidence Rates of HFHL}

The incidence of hearing loss was calculated using all 3 types of neuralgia combined. Of the 107 patients analyzed, 47 (43.9\%) experienced HFHL. Thirty-three $(30.8 \%)$ of the patients had HFHL on the ipsilateral side postoperatively, and $22(20.6 \%)$ of the patients had contralateral HFHL (Table 2). Of the 47 patients with HFHL, $2(4.3 \%)$ experienced nonserviceable (Class C/D) hearing loss, and 17 (36.2\%) had conductive hearing loss after the procedure. In contrast, none of the 60 patients without HFHL had nonserviceable hearing loss, and only 2 (3.3\%) of these patients had conductive hearing loss postoperatively (Table 3). The incidence of nonserviceable hearing loss and conductive hearing loss at all tested frequencies was greater in the ipsilateral ear than in the contralateral ear in patients with HFHL (Table 3).

Of the patients who had a change in pure tone audiometry of $>10 \mathrm{~dB}$ at $4 \mathrm{kHz}, 59 \%$ with loss on the ipsilateral side and $44 \%$ with loss on the contralateral side also had significant hearing loss at $8 \mathrm{kHz}$. Of the patients who had hearing loss at $0.5-2 \mathrm{kHz}, 67 \%$ and $47 \%$ also had hearing loss at 4 and/or $8 \mathrm{kHz}$, respectively. As the audiometric frequency increased, the number of patients with hearing loss also increased (Fig. 1). The mean pure tone threshold in patients also increased as the audiometric frequency increased (Fig. 2). The change in mean pure tone threshold from preoperative to postoperative values showed a greater increase in the ipsilateral ear than the contralateral ear (Fig. 2). Twenty-six percent of the patients had contralateral hearing loss at 4 and/or $8 \mathrm{kHz}$ without ipsilateral hearing loss. Among the 107 patients in the study, 21 (22.6\%) of 93 patients with TGN, $4(50 \%)$ of 8 patients with GN,

TABLE 1. Patient characteristics

\begin{tabular}{lccccc}
\hline & \multicolumn{3}{c}{ HFHL } \\
\cline { 2 - 3 } \cline { 5 - 6 } Characteristic & Ipsilat $(\mathrm{n}=33)$ & Contralat $(\mathrm{n}=22)$ & & Ipsilat $(\mathrm{n}=74)$ & Contralat $(\mathrm{n}=85)$ \\
\cline { 2 - 3 } \cline { 5 - 6 } Sex $(\mathrm{M} / \mathrm{F})$ & $7: 26$ & $6: 16$ & & $23: 51$ & $23: 62$ \\
\hline Side $(\mathrm{It} / \mathrm{rt})$ & $13: 20$ & $8: 14$ & & $29: 45$ & $36: 49$ \\
\hline Age $(\mathrm{yrs} \pm$ SD) & $52.63 \pm 11.91$ & $55.70 \pm 10.60$ & & $51.51 \pm 14.88$ & $51.09 \pm 14.20$ \\
\hline TGN/GN/GPN & $27: 4: 2$ & $20: 1: 1$ & & $66: 5: 3$ & $73: 7: 5$ \\
\hline
\end{tabular}


TABLE 2. Hearing loss at various frequencies among patients who underwent MVD

\begin{tabular}{|c|c|c|c|c|c|c|}
\hline \multirow{2}{*}{$\begin{array}{l}\text { Audiometric Frequency } \\
\qquad(\mathrm{kHz})\end{array}$} & \multicolumn{3}{|c|}{ Side Ipsilat to Op } & \multicolumn{3}{|c|}{ Side Contralat to Op } \\
\hline & $\mathrm{HL}^{*}$ & No $H^{*}$ & $\% \mathrm{HL}$ & $H L^{*}$ & No $H^{*}$ & $\% \mathrm{HL}$ \\
\hline 0.25 & 12 & 95 & 11.21 & 8 & 99 & 7.48 \\
\hline 0.5 & 15 & 92 & 14.02 & 11 & 96 & 10.28 \\
\hline 1 & 21 & 86 & 19.63 & 7 & 100 & 6.54 \\
\hline 2 & 21 & 86 & 19.63 & 8 & 99 & 7.48 \\
\hline 4 & 19 & 88 & 17.76 & 9 & 98 & 8.41 \\
\hline 8 & 27 & 80 & 25.23 & 17 & 90 & 15.89 \\
\hline $4 \& /$ or 8 & 33 & 74 & 30.84 & 22 & 85 & 20.56 \\
\hline
\end{tabular}

$\mathrm{HL}=$ hearing loss.

* Values represent the number of patients.

and $2(33.3 \%)$ of 6 patients with GPN had HFHL. The difference in incidence rates of HFHL was not compared because of to the small sample sizes for patients with GPN and GN compared with TGN.

\section{Intraoperative BAEP Changes and Correlation With Postoperative Hearing Loss}

Statistical analysis of BAEP data revealed no significant difference for the specified parameters between patients with and without HFHL (Table 4). The latency of $\mathrm{wV}$, the amplitude of $\mathrm{wV}$, and the IPL between Waves I and $\mathrm{V}$ were compared for the 2 categories at baseline and the maximum change, but the $\mathrm{p}$ values calculated for each category were not significant $(\mathrm{p}>0.05)$. Stepwise logistic regression analysis did not identify a significant intraoperative variable that increased the odds of HFHL ( $p=$ not significant).

\section{Discussion}

Our present study shows that one-third of patients have ipsilateral HFHL after MVD for TGN, GPN, or GN. We also noted that one-fifth of the patients experienced con-

TABLE 3. Incidence of nonserviceable and conductive hearing loss

\begin{tabular}{lllcc}
\hline \multirow{2}{*}{ Condition } & \multirow{2}{*}{ Criteria } & Affected Side & Yes & No \\
\cline { 4 - 5 } TGN $(n=93)$ & AAO-HNS Class C/D & Ipsilat & 1 & 0 \\
\hline & & Contralat & 1 & 0 \\
\hline & $\mathrm{CHL}$ & Ipsilat & 14 & 0 \\
\hline $\mathrm{GN}(\mathrm{n}=8)$ & $\mathrm{AAO}-\mathrm{HNS}$ Class C/D & Contralat & 2 & 2 \\
\hline & & Ipsilat & 0 & 0 \\
\hline & $\mathrm{CHL}$ & Contralat & 0 & 0 \\
\hline $\mathrm{GPN}(\mathrm{n}=6)$ & $\mathrm{AAO}-\mathrm{HNS}$ Class C/D & Ipsilat & 1 & 0 \\
\hline & & Contralat & 0 & 0 \\
\hline & $\mathrm{CHL}$ & Contralat & 0 & 0 \\
\hline & & Ipsilat & 0 & 0 \\
\hline
\end{tabular}

AAO-HNS = American Academy of Otolaryngology-Head and Neck Surgery;

$\mathrm{CHL}=$ conductive hearing loss. tralateral HFHL after MVD. HFHL after MVD is not well known but has been previously reported in patients who underwent MVD for HFS. This is the first study to demonstrate the presence of HFHL immediately after MVD for TGN, GPN, or GN. Ipsilateral sensorineural hearing loss after MVD could be attributed to 1) stretching of cranial nerve VIII during retraction of the cerebellum, 2) manipulation of the labyrinthine artery and/or the anterior inferior cerebellar artery, 3) direct trauma to the nerve by instruments or nearby coagulation, and 4) new compression of the nerve by the prosthesis interposed between the offending vessel and the affected nerve complex at the end of surgery. ${ }^{23}$ Although drill-induced noise could aggravate or contribute to sensorineural hearing loss by a mechanism of acoustic trauma and reduced bone-conduction thresholds, ${ }^{4,12,13,22}$ it could also contribute to ipsilateral and contralateral HFHL. Our clinical practice includes some patients who complain of hearing disturbance and some who do not, which makes HFHL an incidental finding. We hypothesize that the patients who do not complain do not have the opportunity during their hospital stay to realize their hearing change. Hence we plan to systematically evaluate the short- and long-term clinical effects of these hearing changes in patients by means of a postdischarge quality-of-life survey.

Our results suggest that HFHL was present in patients regardless of the presence of conductive or sensorineural hearing loss. These conditions can mask HFHL during evaluation of the auditory nerve using speech recognition scores or pure tone tests. Noise levels ranging from 117 to $122 \mathrm{~dB}$ in the sound pressure level ${ }^{33}$ have been reported from drilling in the cortical bone and mastoid cavity. These sound levels are equivalent to those at an amplified rock concert in front of speakers or a nearby airplane engine. Our review of the literature indicated that exposure to high-intensity noise damages the hair cells of the cochlear structures. At the subcellular level, the tip links of a hair cell, which are thought to gate mechanoelectrical transduction channels, are broken by high-intensity noise. After acoustical overstimulation, broken tip links were detected and resulted in reduced hair bundle stiffness, disrupted mechanoelectrical transduction, and temporary noise-induced hearing loss. . $^{3,18,35}$

Interestingly, our study also found a high incidence of HFHL in the ear contralateral to the operative side, which is similar to findings about MVD for treatment of HFS. Postoperative contralateral hearing loss has been reported in association with surgeries other than MVD, for example, acoustic neuroma surgery. At least 12 instances of contralateral hearing loss have been documented after acoustic neuroma surgery. ${ }^{31}$ Drilling of the mastoid can temporarily affect both the ipsilateral and contralateral hearing function and contribute to HFHL. ${ }^{5,12,19,36}$ In addition, a lower number of patients had a change in pure tone audiometry at $4 \mathrm{kHz}$ compared to $8 \mathrm{kHz}$ in both the ipsilateral and contralateral ears. This could be because hair cells that detect higher frequencies are damaged first, followed by damage to hair cells that detect lower frequencies. ${ }^{5}$ Some additional mechanisms, including transient loss of cerebrospinal fluid, have been implicated in HFHL. ${ }^{9,20}$ Similar results were also reported in asso- 


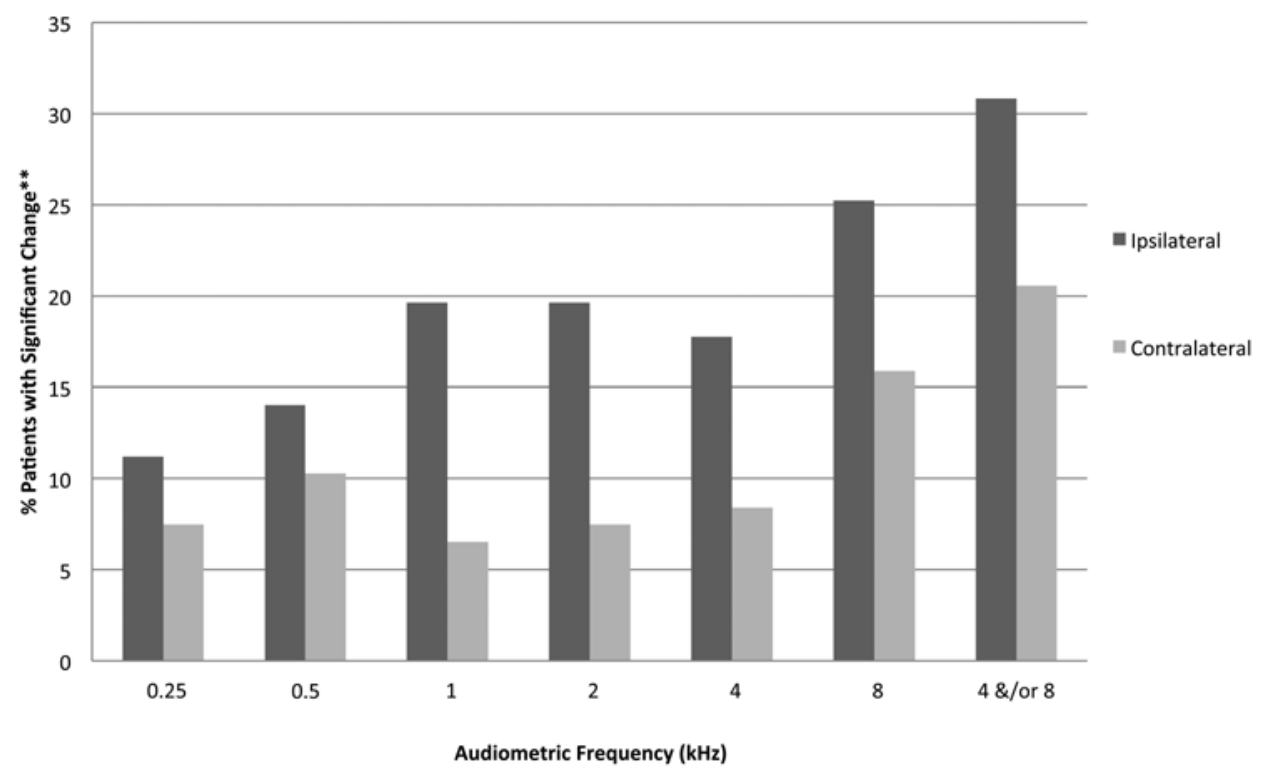

FIG. 1. Incidence of significant changes in PTA in patients after MVD (a significant change in PTA was defined as an increase of > $10 \mathrm{~dB}$ in the PTA threshold postoperatively at the specified frequencies). As the audiometric frequency increased, the number of patients with hearing loss increased. A greater percentage of patients experienced hearing loss on the side ipsilateral to surgery at all calculated frequencies. ${ }^{* *}$ The percentage of patients with a significant change in PTA threshold was calculated according to the following formula: [(number of patients with $>10 \mathrm{~dB}$ increase in PTA at a specified frequency)/(total number of patients)] $\times 100 \%$.

ciation with elective craniotomy when audiograms were performed before and after the procedure. These studies found that drill-generated noise during craniotomy significantly affected high-frequency $(4-6 \mathrm{kHz})$ but not lowfrequency $(0.25-2 \mathrm{kHz})$ hearing. As noted, the short outer hair cells of the high-frequency region have been found to be more vulnerable to sound stimulation than the taller receptor cells in the low-frequency area. ${ }^{3,6,10}$ During MVD for HFS, it is possible that the proximity of cranial nerve
VII to the cochlear nerve may increase the stretching and compression of cranial nerve VIII and thereby increase the probability of HFHL. Interestingly, these surgeries involve cranial nerves that are anatomically farther from the auditory nerve, yet the results are consistent both ipsilaterally and contralaterally. This evidence may indicate that HFHL is the result of a pathological process more complex than simple "nerve stretching."

The change in latency or decrease in the $\mathrm{wV}$ amplitude

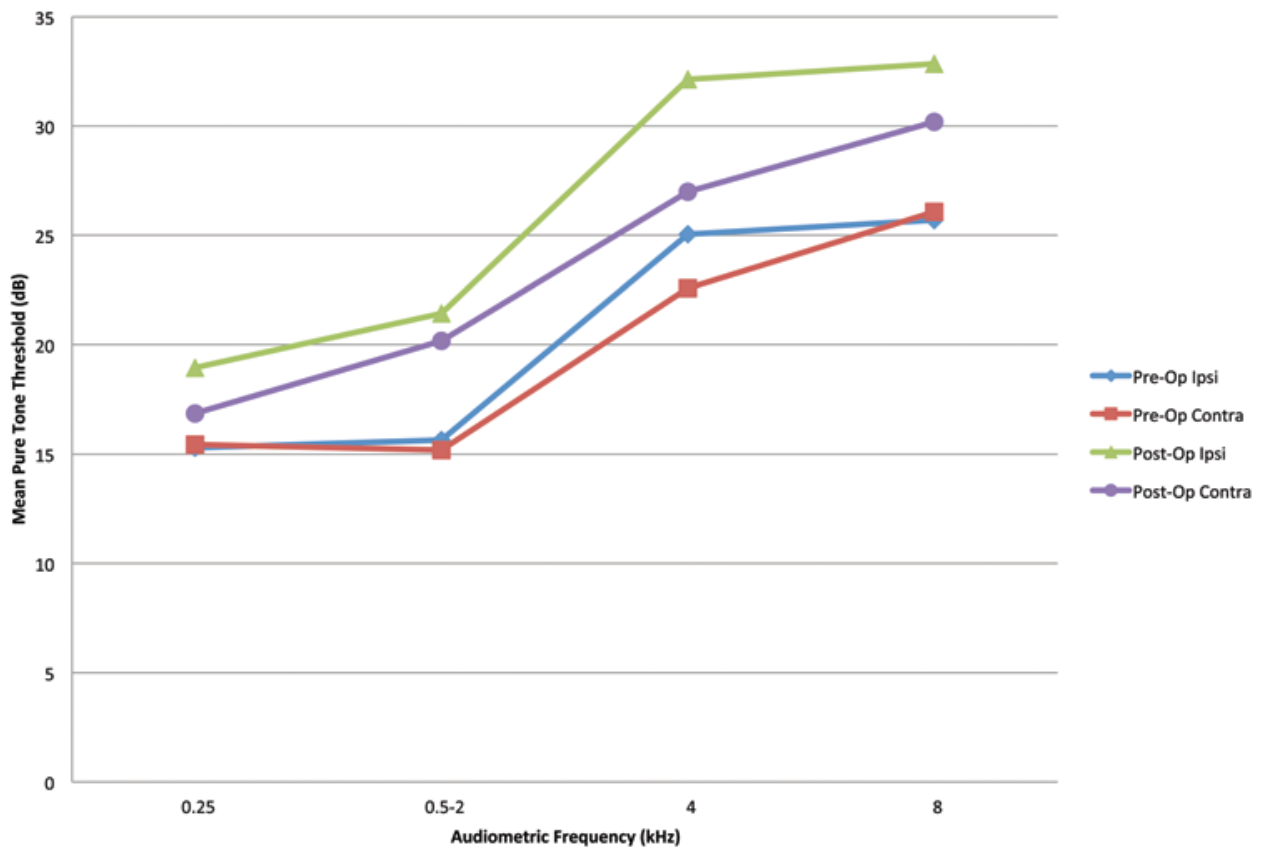

FIG. 2. Mean pure tone threshold at various frequencies. The mean pure tone threshold increased from lower frequencies $(0.25-2$ $\mathrm{kHz}$ ) to higher frequencies ( 4 and $8 \mathrm{kHz}$ ). For both the ipsilateral (Ipsi) and the contralateral (Contra) sides, the mean pure tone threshold increased after the surgery. Figure is available in color online only. 
TABLE 4. Incidence of significant change in intraoperative BAEP monitoring between HFHL and no high-frequency hearing loss patients

\begin{tabular}{lccc}
\hline \multicolumn{1}{c}{ Variable } & HFHL & NHFHL & p Value \\
\hline Latency wV $(\mathrm{ms}) \pm \mathrm{SD}$ & & & \\
\hline Baseline & $6.51 \pm 0.40$ & $6.46 \pm 0.40$ & 0.52 \\
\hline Change max & $8.46 \pm 1.98$ & $7.79 \pm 1.57$ & 0.061 \\
\hline Change max vs baseline & $1.29 \pm 0.28$ & $1.21 \pm 0.24$ & 0.14 \\
\hline Amplitude wV (mV) \pm SD & & & \\
\hline Baseline & $0.33 \pm 0.12$ & $0.32 \pm 0.10$ & 0.93 \\
\hline Change max & $0.24 \pm 0.17$ & $0.25 \pm 0.12$ & 0.75 \\
\hline Change max vs baseline & $0.70 \pm 0.44$ & $0.81 \pm 0.40$ & 0.22 \\
\hline IPL wl-V (ms) \pm SD & & & \\
\hline Baseline & $4.53 \pm 0.39$ & $4.50 \pm 0.33$ & 0.62 \\
\hline Change max & $6.79 \pm 2.91$ & $5.87 \pm 2.25$ & 0.074 \\
\hline Change max vs baseline & $1.51 \pm 0.63$ & $1.29 \pm 0.50$ & 0.053 \\
\hline
\end{tabular}

$\mathrm{NHFHL}=$ no high-frequency hearing loss; $\mathrm{wV}=$ Wave $\mathrm{V} ; \mathrm{wl}-\mathrm{V}=$ Waves $\mathrm{I}-\mathrm{V}$.

of BAEPs has been reported to be a predictor of hearing loss. ${ }^{11,16,29}$ In the study reported here, no significant difference was found between the groups with and without HFHL during any stage of MVD for any other BAEP waveform latency or amplitude measurements, including Waves I, III, and V and interpeak latencies. HFHL probably was not secondary to stretching of the auditory nerve during MVD but likely was induced by high-intensity drilling noise during craniotomy early in the procedure. ${ }^{34}$ Studies performed on hair cells in animal models have reported evidence of reestablished signal transduction upon regeneration of the tip links of hair cells in cultured explants 6 hours after the stimulus, ${ }^{35}$ or in vivo after $24-120$ hours. ${ }^{15}$ The time course of hair cell tip link regeneration suggests that this process may underlie recovery from temporary threshold shift induced by noise exposure. ${ }^{26,35}$

Our study, which was designed to further evaluate our findings of HFHL after MVD for TGN, GN, or GPN, has some limitations. Our study population included patients who had preoperative and postoperative audiograms, so it is possible that the incidence of HFHL could be a bias toward people who obtained audiograms. These patients may have had symptoms and hence may have wanted to undergo diagnostic testing. We did not procure long-term follow-up audiograms to evaluate hearing improvement. These tests might be useful because studies in humans ${ }^{14}$ have shown that the changes take place in the near-toimmediate term after the procedure, and the majority of patients may improve.

\section{Conclusions}

HFHL primarily on the ipsilateral side may be due to drill-induced noise and/or transient loss of cerebrospinal fluid during MVD for TGN, GPN, or GN. Changes in intraoperative BAEPs during MVD were not useful in predicting HFHL. Follow-up studies and repeat audiological examinations may be helpful in evaluating the time course and prognosis of HFHL.

\section{References}

1. American Academy of Otolaryngology-Head and Neck Surgery: Committee on Hearing and Equilibrium guidelines for the evaluation of hearing preservation in acoustic neuroma (vestibular schwannoma). Otolaryngol Head Neck Surg 113:179-180, 1995

2. American Electroencephalographic Society: Guidelines for intraoperative monitoring of sensory evoked potentials. J Clin Neurophysiol 11:77-87, 1994

3. Chan E, Suneson A, Ulfendahl M: Acoustic trauma causes reversible stiffness changes in auditory sensory cells. Neuroscience 83:961-968, 1998

4. Clark WW, Bohne BA: Effects of noise on hearing. JAMA 281:1658-1659, 1999

5. da Cruz MJ, Fagan P, Atlas M, McNeill C: Drill-induced hearing loss in the nonoperated ear. Otolaryngol Head Neck Surg 117:555-558, 1997

6. Doménech J, Carulla M, Traserra J: Sensorineural high-frequency hearing loss after drill-generated acoustic trauma in tympanoplasty. Arch Otorhinolaryngol 246:280-282, 1989

7. Farzanegan G, Ghasemi M, Panahi F, Raza M, Alghasi M: Does drill-induced noise have an impact on sensorineural hearing during craniotomy procedure? Br J Neurosurg 24:40-45, 2010

8. Frank T: ANSI update: maximum permissible ambient noise levels for audiometric test rooms. Am J Audiol 9:3-8, 2000

9. Guillaume DJ, Knight K, Marquez C, Kraemer DF, Bardo DM, Neuwelt EA: Cerebrospinal fluid shunting and hearing loss in patients treated for medulloblastoma. J Neurosurg Pediatr 9:421-427, 2012

10. Hamernik RP, Patterson JH, Turrentine GA, Ahroon WA: The quantitative relation between sensory cell loss and hearing thresholds. Hear Res 38:199-211, 1989

11. Hatayama T, Møller AR: Correlation between latency and amplitude of peak V in the brainstem auditory evoked potentials: intraoperative recordings in microvascular decompression operations. Acta Neurochir (Wien) 140:681-687, 1998

12. Hegewald M, Heitman R, Wiederhold ML, Cooper JC, Gates GA: High-frequency electrostimulation hearing after mastoidectomy. Otolaryngol Head Neck Surg 100:49-56, 1989

13. Jiang D, Bibas A, Santuli C, Donnelly N, Jeronimidis G, O'Connor AF: Equivalent noise level generated by drilling onto the ossicular chain as measured by laser Doppler vibrometry: a temporal bone study. Laryngoscope 117:10401045,2007

14. Karatas E, Miman MC, Ozturan O, Erdem T, Kalcioglu MT: Contralateral normal ear after mastoid surgery: evaluation by otoacoustic emissions (mastoid drilling and hearing loss). ORL J Otorhinolaryngol Relat Spec 69:18-24, 2007

15. Kurian R, Krupp NL, Saunders JC: Tip link loss and recovery on chick short hair cells following intense exposure to sound. Hear Res 181:40-50, 2003

16. Lee SH, Song DG, Kim S, Lee JH, Kang DG: Results of auditory brainstem response monitoring of microvascular decompression: a prospective study of 22 patients with hemifacial spasm. Laryngoscope 119:1887-1892, 2009

17. Lovely TJ, Jannetta PJ: Surgical management of geniculate neuralgia. Am J Otol 18:512-517, 1997

18. Migirov L, Wolf M: Influence of drilling on the distortion product otoacoustic emissions in the non-operated ear. ORL J Otorhinolaryngol Relat Spec 71:153-156, 2009

19. Park K, Hong SH, Hong SD, Cho YS, Chung WH, Ryu NG: Patterns of hearing loss after microvascular decompression for hemifacial spasm. J Neurol Neurosurg Psychiatry 80:1165-1167, 2009

20. Park P, Toung JS, Smythe P, Telian SA, La Marca F: Unilateral sensorineural hearing loss after spine surgery: Case report and review of the literature. Surg Neurol 66:415-419, 2006

21. Patel A, Kassam A, Horowitz M, Chang YF: Microvascu- 
lar decompression in the management of glossopharyngeal neuralgia: analysis of 217 cases. Neurosurgery 50:705-711, 2002

22. Pau HW, Just T, Bornitz M, Lasurashvilli N, Zahnert T: Noise exposure of the inner ear during drilling a cochleostomy for cochlear implantation. Laryngoscope 117:535-540, 2007

23. Polo G, Fischer C, Sindou MP, Marneffe V: Brainstem auditory evoked potential monitoring during microvascular decompression for hemifacial spasm: intraoperative brainstem auditory evoked potential changes and warning values to prevent hearing loss-prospective study in a consecutive series of 84 patients. Neurosurgery 54:97-106, 2004

24. Rizvi SS, Goyal RN, Calder HB: Hearing preservation in microvascular decompression for trigeminal neuralgia. Laryngoscope 109:591-594, 1999

25. Rupa V, Saunders RL, Weider DJ: Geniculate neuralgia: the surgical management of primary otalgia. J Neurosurg 75:505-511, 1991

26. Schneider ME, Belyantseva IA, Azevedo RB, Kachar B: Rapid renewal of auditory hair bundles. Nature 418:837-838, 2002

27. Shah A, Nikonow T, Thirumala P, Hirsch B, Chang Y, Gardner P, et al: Hearing outcomes following microvascular decompression for hemifacial spasm. Clin Neurol Neurosurg 114:673-677, 2012

28. Shargorodsky J, Curhan SG, Curhan GC, Eavey R: Change in prevalence of hearing loss in US adolescents. JAMA 304:772-778, 2010

29. Sindou M, Fobé JL, Ciriano D, Fischer C: Hearing prognosis and intraoperative guidance of brainstem auditory evoked potential in microvascular decompression. Laryngoscope 102:678-682, 1992

30. Thirumala PD, Kassasm AB, Habeych M, Wichman K, Chang YF, Gardner P, et al: Somatosensory evoked potential monitoring during endoscopic endonasal approach to skull base surgery: analysis of observed changes. Neurosurgery (1 Suppl Operative) 69:ons64-ons76, 2011

31. Togashi S, Maruya J, Nerome C, Nishimaki K, Kimura H,
Minakawa T: Contralateral hearing loss after acoustic neuroma surgery. J Clin Neurosci 21:863-865, 2014

32. Walker JJ, Cleveland LM, Davis JL, Seales JS: Audiometry screening and interpretation. Am Fam Physician 87:41-47, 2013

33. Yin X, Strömberg AK, Duan M: Evaluation of the noise generated by otological electrical drills and suction during cadaver surgery. Acta Otolaryngol 131:1132-1135, 2011

34. Ying T, Thirumala P, Shah A, Nikonow T, Wichman K, Holmes M, et al: Incidence of high-frequency hearing loss after microvascular decompression for hemifacial spasm. $\mathbf{J}$ Neurosurg 118:719-724, 2013

35. Zhao Y, Yamoah EN, Gillespie PG: Regeneration of broken tip links and restoration of mechanical transduction in hair cells. Proc Natl Acad Sci U S A 93:15469-15474, 1996

36. Zou J, Bretlau P, Pyykkö I, Starck J, Toppila E: Sensorineural hearing loss after vibration: an animal model for evaluating prevention and treatment of inner ear hearing loss. Acta Otolaryngol 121:143-148, 2001

\section{Author Contributions}

Conception and design: Thirumala. Acquisition of data: Thirumala, Meigh, Dasyam, Shankar, KRK Sarma, DRK Sarma. Analysis and interpretation of data: Thirumala, Meigh, Dasyam. Drafting the article: Thirumala, Meigh, Dasyam. Critically revising the article: Thirumala, Meigh, Habeych, Crammond, Balzer. Reviewed submitted version of manuscript: Thirumala, Meigh, Habeych, Crammond, Balzer. Approved the final version of the manuscript on behalf of all authors: Thirumala. Statistical analysis: Meigh, Dasyam. Administrative/technical/material support: Thirumala. Study supervision: Thirumala.

\section{Correspondence}

Parthasarathy D. Thirumala, Center for Clinical Neurophysiology, Department of Neurological Surgery, UPMC Presbyterian, 200 Lothrop St., Ste. B-400, Pittsburgh, PA 15213. email: thirumalapd $@$ upmc.edu. 